Article

\title{
The Effects of One-Child Policy on the Economy and the Environment in an OLG Framework
}

\author{
Peter J. Stauvermann ${ }^{1}$, Jin $\mathrm{Hu}^{1}$ and Ronald Ravinesh $\mathrm{Kumar}^{2,3 *}$ \\ 1 School of Global Business \& Economics, Changwon National University, 641-773 Changwon, Republic \\ of Korea; pjsta@changwon.ac.kr \\ 1 School of Global Business \& Economics, Changwon National University, 641-773 Changwon, Republic \\ of Korea; ¡im hu@126.com \\ 2 Informetrics Research Group, Ton Duc Thang University, Ho Chi Minh City, Vietnam. \\ 3 Faculty of Social Sciences and Humanities, Ton Duc Thang University, Ho Chi Minh City, Vietnam; \\ ronald.ravinesh.kumar@tdt.edu.vn
}

* Correspondence: Informetrics Research Group, Ton Duc Thang University, Ho Chi Minh City, Vietnam.

\begin{abstract}
In this paper we take China's one child policy as an example and investigate its environmental impact. We develop a model for an economy using a standard overlapping generation model extended with human capital, endogenous fertility, and changing life expectancy. To model the environmental impact of economic activities, we use a modified IPAT model. We show that China's one child has a very strong positive impact on the environment, particularly if we consider the whole human legacy.
\end{abstract}

Keywords: one-child policy; environment; OLG model; fertility; human capital; child tax

\section{Introduction}

In the light of the fact that 197 nations have agreed on the October $5^{\text {th }}, 2016$ in Paris ${ }^{1}$ to take measures to keep the average world temperature increase to at most 2 degree Celsius by 2050, enormous efforts have to be taken to lower the average level of $\mathrm{CO} 2$ emissions per capita from 4.97 metric tons $^{2}$ in 2014 to the required level of around 1.5-1.8 tons per capita [1] given the current world population. Additionally, according to United Nations Environmental Program (UNEP 2016) the current agreed national policy goals regarding greenhouse gas (GHG) emissions are not sufficient to keep the average world temperature increase below the targeted 1.5-2 degree Celsius. If the policy goals remain unchanged, the temperature is expected to rise from 2.9 to 3.4 degree Celsius, or in terms of emissions, the worldwide yearly GHG emissions will be between 57.9 and 63.1 giga tons (Gt) per year in 2030. While a desirable a policy goal is to have emissions less than $43.5 \mathrm{Gt}$ per year, ${ }^{3}$ we note that the total GHG emissions are still increasing (Figure 1).

\footnotetext{
${ }^{1}$ http://unfccc.int/paris agreement/items/9485.php

${ }^{2}$ If not otherwise stated all data is taken from the data of the World Bank

${ }^{3}$ It should be noted if this emission level will be reached there is a $66 \%$ probability that the temperature rise will not more than 2 degree Celsius.
} 


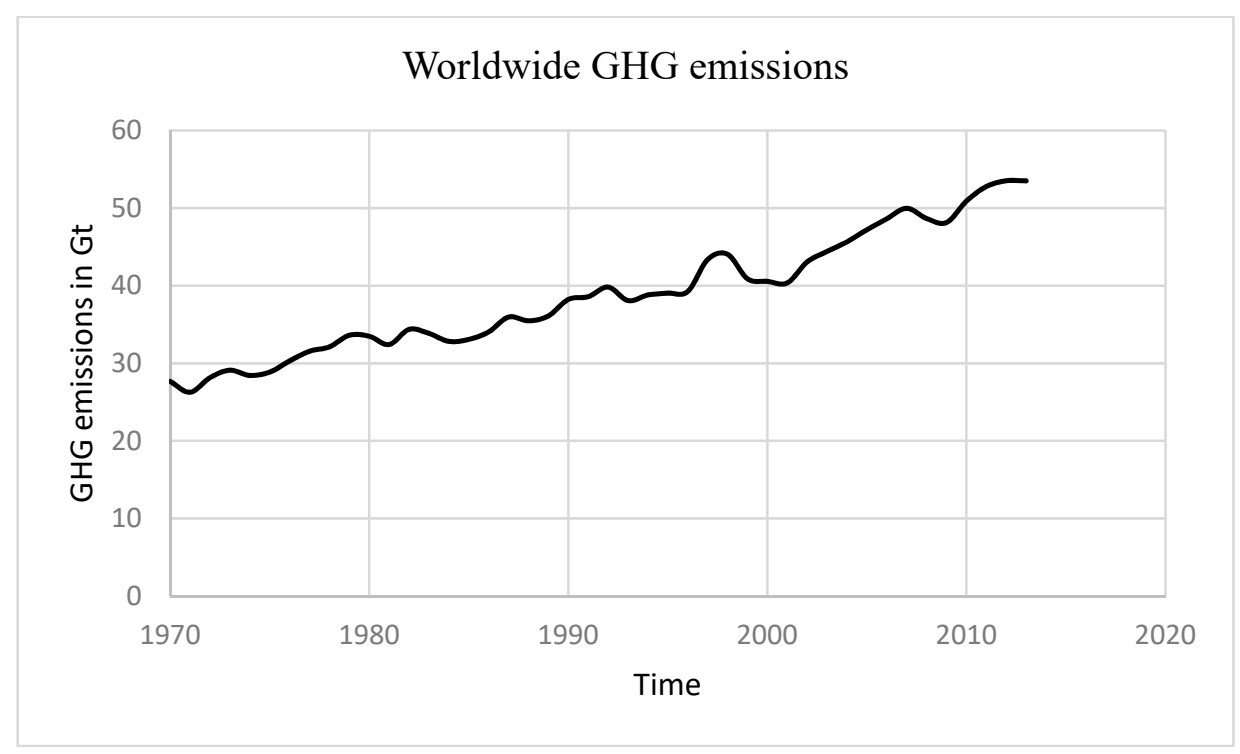

Figure 1

In our view the main obstacle is that it is politically very difficult to change the consumption pattern of all members of society without being confronted with a strong political opposition. Also, in the long run, it is probably much easier to apply a restrictive population policy to lower the total level of emissions. Another reason for our study is based on the fact that the United Nations estimates that the world population will increase from currently 7.6 billion people to 11.2 billion people in 2100 . It is hardly possible to imagine how the agreed sustainability goals can be reached given that the world population will increase by $47 \%$ in the next 80 years. Moreover, the resulting additional demands for agricultural land and water resources to produce a sufficient amount of food are inevitable. According to the FAO [2], the world food production will need to be increased by $70 \%$ in 2050. Despite the assumption that only $20 \%$ of the additional food demand should be satisfied by extending agricultural land, the environmental consequences of such a land use change in terms of biodiversity and climate change are enormous. ${ }^{4}$ Therefore, population growth is a crucial factor influencing food security, climate change and overall sustainability path.

Thus, the aim of this study is to illustrate the relationship between the population policy, economic growth and environment. The impact of population growth on the economy and environment has been at the center of economic discussion for some time. Dietz and Rosa [4] note that the recognition of negative impact of population growth on economic wellbeing goes back to Heroditus (484-425 BC) and the negative impact of population growth on the environment to Seneca, the younger (4 BC-AD 65). In modern times, Malthus [5] was the first to analyze the relationship between population, economic wellbeing and the natural environment. Malthus predicted that continued population growth in a world with limited resources would lend itself to poverty and famine. Malthus' general considerations regained popularity through Ehrlich's [6] publication on "Population bomb". He emphasized that overpopulation will lead to unavoidable catastrophic famines. Although his predictions failed to become true as fast as he has forecasted, they will probably become true if humankind fails to manage the climate change problem.

In a recent study, Wynes and Nicholas [7] investigate the most effective individual actions to reduce the human impact on the global warming. Additionally, they examine the extent to which the relatively effective measures and actions are recommended and promoted by the governments of Australia, USA,

\footnotetext{
${ }^{4}$ It should be noted that $30 \%$ of the GHG emissions can be traced back to food production [3].
} 
Canada and the European Union, who are responsible for about $26 \%$ of all CO2 (2014) and $24 \%$ of all greenhouse gas emissions (2012). The outcome of Wynes and Nicholas [7] is that, one child less has the strongest impact among other human actions, on reducing GHG emissions per year (between 23.7 and 117.7 tons). Other actions identified in the study were: forgoing car use, sacrificing airplane flights, and purchase of green energy which reduces GHG emissions in the order of 1.0 to 5.3 tons per annum, 0.7 to 2.8 tons per flight, and 0.1 to 2.5 tons per year, respectively. Although, the reduction of the number of children is the most effective measure, this action is neither recommended nor proposed by the governments of Canada, USA, Australia or the European Union, due to political and/or religious reasons, and the fact that environmental effects caused by the number of children are largely underestimated.

Several studies [4, 8-15] take only the environmental related actions of humans into consideration, which are directly related to them, and not the environmental damages caused by their descendants. For the short-run, such environmental impact analysis is adequate. In contrast, Murtaugh and Schlax [16] and later Wynes and Nicholas [7] propose to take the full carbon legacy of humans into account. Their argument is that a human does not only pollute directly but indirectly via reproduction, because the children can only negatively influence the environment if they are born. Further, the grandchildren will also contribute to emissions, and they only can do so, if they and their parents were born. Consequently, Murtaugh and Schlax [16] argue that parents are responsible for their emission-generating actions and for a part of the emissions caused by all dynastic successors. As such, the weighting of emissions is related to the fractional genetic units. Thus, $50 \%$ of the emissions of children are related to the mother, an additional $25 \%$ of the emissions of the grandchildren are related to the same mother, and so on. In other words, the fraction of genetic units or the weight of a member of the n-th succeeding generation is $\left(\frac{1}{2}\right)^{n}$. According to the calculation method of Murtaugh and Schax [16], taking the United Nations medium variant of population projection as given and assuming three scenarios -optimistic, constant and pessimistic ${ }^{5-}$ the GHG emission reduction per unborn child for China (2005) was 228 tons, 1,384 tons and 2,023 tons, respectively. Unfortunately, the per capita GHG emissions in China has reached recently 9.2 tons per year, thus the actual reduction effect would be much higher.

The only country which applied legal measures to control population growth was China with its one child policy, which dates implicitly back to the early 1970s [17]. The considerations above indicate that the one-child policy has a negative (reducing) effect on GHG emissions and environmental degradation. Beside the environmental effects caused by the one-child policy, the economic impact is equally impressive, especially when we consider the economic development of China's economy since 1980. However, this does not mean that the one child policy was the only important policy measure which made the China's growth possible, but it has played a significant role. The reasoning for this is provided by the argument of Becker's quality-quantity trade-off [18-19] which proposes that the quantity of children is to be substituted by the quality of children, the latter generally referring to proper child development to improve human capital. ${ }^{6}$ Hence, the result is an increased investment in education and hence human capital accumulation, which is one of the most important drivers of economic growth [26].

To model the one-child policy, we introduce a child tax system, in which the there is no tax imposed for the first child but for all others, that is second child and onwards, taxes are imposed. This seems to be an appropriate approach to model the one child policy, because the taxes act as fines for violating the

\footnotetext{
${ }^{5}$ The optimistic scenario assumes that the emissions decrease linearly from 2005 to 2100 to a value of 0.5 tons GHG emission per capita and year. The constant scenario requires that the GHG emissions remain constant at the level of 2005, which was 3.62 tons of GHG emissions per capita and year in China. The pessimistic scenario assumes a linear increase from 3.62 tons in 2005 to a value of 5.43 tons per capita and year in 2100.

${ }^{6}$ Becker's theory is confirmed empirically among others by [20-25].
} 
policy. According to Tietenberg and Lewis [27], the economic incentive scheme of China's one child policy consisted of priority in education and housing, subsidized health care, and additional subsidized food for parents with one child. For parents with two or more children received a reduction of 5 percent in the total income for the third child and 6 percent for the fourth child, and so on. Additionally, families were denied access to further subsidized grain beyond that which they would already receive for their first two children. ${ }^{7}$ The outcome was a dramatic fall in the total fertility rate from 5.7 in 1970 to 1.5 by 2015.

The aim of this study is to analyze the impact of a child-tax on economic growth environmental degradation. First, we develop a theoretical model of an economy, so that we can derive the economic and environmental effects of one child policy. Second, we show that the one child policy is generally a measure to accelerate economic growth without interfering the global climate objectives and that this policy is useful for countries which exhibit a high fertility rate.

We apply an extended Diamond [28] OLG model similar to Stauvermann and Kumar [29-31]. The underlying idea goes back to de la Croix and Doepke $[33,34]$. The advantage of this approach is that it functionalizes the idea of Becker's [18] quality-quantity tradeoff. Further, we extend the model by considering aging as proposed by Cipriani [35] and Stauvermann and Kumar [29] for a small open economy.

The rest of the paper is organized as follows. In Section 2, we introduce the model and derive the respective equilibrium. In Section 3, we apply the equilibrium outcomes to the IPAT model $[4,12,36-38]$ to derive the environmental or emission equilibrium. ${ }^{8}$ In Section 4 , we calibrate the model to generate the outcomes for the transition path; and in Section 5, conclusion follows.

\section{The model}

We use a three generations OLG model of Diamond [28], where we make the simplifying assumption that an individual has a neutral gender and can give birth to children. With this assumption we avoid the problems of matching. Further, the parent takes all decisions for her children in their first period of life. In the second period of life, the children are adults, who supply labor inelastically, give birth to a number of children $n_{t}$, pay for their education $q_{t} h_{t} w_{t}$, consume $c_{t}^{1}$ units and save a part of their income $s_{t}$. The expression of the educational expenditures $q_{t} h_{t} w_{t}$ is a product of the wage income fraction $q_{t}$ spent for the education, the human capital stock of the parent $h_{t}$ and the wage rate per human capital unit $w_{t}$.

In line with Cipriani [35] and Ehrlich and Lui [39], we assume that the children will be alive in the third period of life with probability $\rho$. Assuming a perfectly competitive financial market, the risk-free return on savings is given by $\frac{R_{t+1}}{\rho}$. The representative agent derives his/her utility from the consumption in the second $c_{t}^{1}$ and third period $c_{t+1}^{2}$, the number of children (their quantity) $n_{t}$, and the level of the children's human capital stock (their quality) $h_{t+1}$. The utility function follows from de la Croix and Doepke [25,26,40] and Stauvermann and Kumar [29-31].

$$
U_{t}\left(c_{t}^{1}, c_{t+1}^{2}, n_{t}, q_{t}\right)=\ln \left(c_{t}^{1}\right)+\rho \chi \ln \left(c_{t+1}^{2}\right)+\phi\left(\ln \left(n_{t}\right)+\psi \ln \left(h_{t+1}\right)\right)
$$

\footnotetext{
${ }^{7}$ It cannot be excluded that coercive measures like forced abortions were taken to enforce the one child policy.

${ }^{8}$ IPAT model was originally introduced by Ehlich and Holden [36], where I refers to the environmental impact, $\mathrm{P}$ the population, A affluence, and T the technology.
} 
where $\{\chi, \phi, \psi\} \in(0,1)$. The variable $\chi$ is the subjective discount factor, $\phi$ represents the preference for the quantity of children and $\phi \psi$ represents the preference for the quality or education of children. The variable $\rho$ is a function representing the probability to be alive in the third period of life. We allow for aging of the society as proposed by Ehrlich and Lui [39], where individuals enjoy the third period of life with probability $\rho$. Considering the results of Cutler et al [41], we assume that this survival probability depends positively on the existing average human capital per capita $\overline{h_{t}}$ which is taken as given by the individuals. Similar to Blackburn and Cipriani [42], Cipriani and Makris [43] and Cipriani [35] we assume that a maximum length of life. Hence,

$$
\rho=\rho\left(\overline{h_{t}}\right),
$$

where we assume the following properties:

(i) $0<\underline{\rho} \leq \rho\left(\overline{h_{t}}\right) \leq 1$,

(ii) $\rho^{\prime}\left(\overline{h_{t}}\right)>0$,

(iii) $\rho^{\prime \prime}\left(\overline{h_{t}}\right)<0$,

(iv) $\lim _{h_{t} \rightarrow \infty} \rho^{\prime}\left(\overline{h_{t}}\right)=0$,and

(v) $\lim _{h_{t} \rightarrow \infty} \rho\left(\overline{h_{t}}\right)=1$.

The human capital production function is, without loss of generality, a special case used by de la Croix and Doepke [33,34]:9

$$
h_{t+1}=\Omega h_{t} q_{t}^{m},
$$

where $\Omega>0$ and $m \in$ ]0,1[. The variable $q_{t} \geq 0$ represents parent's investments in the education per child. It should be noted that we discard the possibility of no investment in education because we want to concentrate on the effects of human capital. Human capital serves two purposes in our study. First, human capital is the driver of growth [44-46], and second, human capital is considered synonymous to the quality of a child $[18,19]$.

To model the one-child policy, we consider in our model a half-child policy. That is, a half-child is tax free and all other children are taxed with the wage rate tax of $\tau^{c} \epsilon[0,1]$. To balance the government budget, we assume the tax revenue is redistributed as a lump-sum transfer $T_{t}$. Then the child tax schedule can be written as:

$$
\mathrm{T}_{t}^{c}=\left\{\begin{array}{c}
0, \text { if } n_{t} \leq \frac{1}{2} \\
w_{t} h_{t} \tau^{c}\left(n_{t}-\frac{1}{2}\right), \text { if } n_{t}>\frac{1}{2}
\end{array}\right.
$$

Assuming that all individuals are identical, a balanced government budget requires in per capita terms that the tax revenue equals lump-sum transfer: $T_{t}=\mathrm{T}_{t}^{c}$.

Thus, we consider the case where the number of children exceeds the threshold value. ${ }^{10}$ Therefore, the budget constraint in the second period of life is given by:

\footnotetext{
${ }^{9}$ We forgo considering positive externalities in the human capital production to make our arguments stronger.

${ }^{10}$ The case where the number of children is less than half is irrelevant and in the equilibrium, the number of children will always be bigger than a half.
} 


$$
\mathrm{c}_{t}^{1}=w_{t} h_{t}\left(1+T_{t}-n_{t}\left(e+q_{t}\right)-\tau^{c}\left(n_{t}-\frac{1}{2}\right)\right)-s_{t}
$$

where the variable $e$ represents the fraction of the wage income which has to be spent to raise a child. In other words, the expenditures $e n_{t} w_{t} h_{t}$ represent the pure child-rearing costs. The budget constraint of an individual in the third period of life is:

$$
\mathrm{c}_{t+1}^{2}=\frac{R_{t} s_{t}}{\rho\left(\overline{h_{t}}\right)}
$$

Then the individual utility maximization problem becomes:

$$
\begin{gathered}
\max _{\left\{s_{t}, n_{t}, q_{t}\right\}} U_{t}\left(s_{t}, n_{t}, q_{t}\right)=\ln \left(w_{t} h_{t}\left(1+T_{t}-n_{t}\left(e+q_{t}\right)-\tau^{c}\left(n_{t}-\frac{1}{2}\right)\right)-s_{t}\right)+\rho\left(\overline{h_{t}}\right) \chi \ln \left(\frac{R_{t} s_{t}}{\rho\left(\overline{h_{t}}\right)}\right)+\phi\left(\ln \left(n_{t}\right)+\right. \\
\left.\mu \ln \left(\Omega h_{t} q_{t}^{m}\right)\right) .
\end{gathered}
$$

Because of the fact that all individuals are identical, we set $\overline{h_{t}}$ equal to $h_{t}$. From the maximization problem (7), three optimality conditions are obtained:

$$
\begin{gathered}
\frac{1}{w_{t} h_{t}\left(1+T_{t}-n_{t}\left(e+q_{t}\right)-\tau^{c}\left(n_{t}-\frac{1}{2}\right)\right)-s_{t}}=\frac{\chi \rho\left(h_{t}\right)}{s_{t}} \\
\frac{w_{t} h_{t}\left(e+q_{t}+\tau^{c}\right)}{w_{t} h_{t}\left(1+T_{t}-n_{t}\left(e+q_{t}\right)-\tau^{c}\left(n_{t}-\frac{1}{2}\right)\right)-s_{t}}=\frac{\phi}{n_{t}^{\prime}} \\
\frac{w_{t} h_{t} n_{t}}{w_{t} h_{t}\left(1+T_{t}-n_{t}\left(e+q_{t}\right)-\tau^{c}\left(n_{t}-\frac{1}{2}\right)\right)-s_{t}}=\frac{\psi \phi m}{q_{t}} .
\end{gathered}
$$

Using the balanced government budget, the system of three equations is solved for the three choice variables. First, the optimal investments in education are:

$$
q^{*}=\frac{\psi m\left(e+\tau^{c}\right)}{1-\psi m}
$$

Then, inserting (11) into the human capital production function (3) delivers:

$$
h_{t+1}=\Omega h_{t}\left(\frac{\psi m\left(e+\tau^{c}\right)}{1-\psi m}\right)^{m}
$$

And the growth factor of human capital is:

$$
G^{h}=\frac{h_{t+1}}{h_{t}}=\Omega\left(\frac{\psi m\left(e+\tau^{c}\right)}{1-\psi m}\right)^{m}
$$

To avoid pathological cases, we assume $\Omega>1 /\left(\frac{\psi m\left(e+\tau^{c}\right)}{1-\psi m}\right)^{m}$ is fulfilled. From (11) and (13), the following proposition is derived:

Proposition 1: The introduction or increase of a child tax will increase the investments in education and increase of the human capital growth factor.

Proof:

$\frac{\partial q^{*}}{\partial \tau^{c}}=\frac{\psi m}{1-\psi m}>0$

and 
$\frac{\partial G^{h}}{\partial \tau^{c}}=\frac{m \Omega\left(\frac{\psi m\left(e+\tau^{c}\right)}{1-\psi m}\right)^{m}}{\left(e+\tau^{c}\right)}>0$.

We get for the optimal savings $\left(s_{t}^{*}\right)$ and number of children $\left(n_{t}^{*}\right)$ as:

$$
\begin{aligned}
s_{t}^{*} & =\frac{\rho\left(h_{t}\right)\left(e+\tau^{c}\right) \chi w_{t} h_{t}}{\chi \rho\left(h_{t}\right)\left(e+\tau^{c}\right)+\tau^{c}(1+m \psi \phi)+e(1+\phi)} . \\
n_{t}^{*} & =\frac{\phi(1-\psi m)}{\chi \rho\left(h_{t}\right)\left(e+\tau^{c}\right)+\tau^{c}(1+m \psi \phi)+e(1+\phi)} .
\end{aligned}
$$

Proposition 2: In the short run, an increase of the child tax leads to an increase of the savings and a reduction of the number of children.

Proof:

$\frac{\partial s_{t}^{*}}{\partial \tau^{c}}=\frac{\rho\left(h_{t}\right) \chi w_{t} h_{t} \phi(1-m \psi) e}{\left[\chi \rho\left(h_{t}\right)\left(e+\tau^{c}\right)+\tau^{c}(1+m \psi \phi)+e(1+\phi)\right]^{2}}>0$

and

$\frac{\partial n_{t}^{*}}{\partial \tau^{c}}=-\frac{(1-m \psi) \phi\left(1+m \psi \phi+\chi \rho\left(h_{t}\right)\right)}{\left[\chi \rho\left(h_{t}\right)\left(e+\tau^{c}\right)+\tau^{c}(1+m \psi \phi)+e(1+\phi)\right]^{2}}<0$, q.e.d.

The intuition behind the two propositions is as follows: an increase of the child tax raises the childrearing costs, which means that the costs of education becomes relatively less expensive and both effects lead to a decline of the number of children and an increase of the investments in education. The latter effect will result in an increase of the growth rate of human capital. Additionally, the savings will increase because a shift of current consumption into the future will take place.

It is noted that the optimal values of the savings and number of children depend on the life expectancy $\rho\left(h_{t}\right)$, which strives to a value of one in the long run.

On the supply side of the economy, we use a standard neoclassical production function:

$$
Y_{t}=F\left(K_{t}, H_{t}\right)
$$

where $Y_{t}$ represents the aggregate production, $K_{t}$ the aggregate physical capital stock, and $H_{t}=$ $h_{t} N_{t}$ the aggregate stock of human capital. The production function exhibits the usual diminishing marginal productivities in each input factor, fulfills the Inada conditions and is linear homogenous. Hence, we can rewrite (16) in terms of the production per human capital unit: ${ }^{11}$

$$
y_{t}=f\left(k_{t}\right)
$$

where $y_{t}=\frac{Y_{t}}{h_{t} N_{t}}$ and $k_{t}=\frac{K_{t}}{h_{t} N_{t}}$.

Without loss of generality, we assume a depreciation rate of physical capital of 100 percent per period. Assuming perfectly competitive good and factor markets, the wage rate per human capital unit and the interest factor are:

${ }^{11}$ Expressed in per human capital units, the production function becomes $f\left(k_{t}\right)=F\left(\frac{K_{t}}{L_{t}}, 1\right)$. We assume that the corresponding Inada conditions hold: $f(0)=0 ; f(\infty)=\infty ; f^{\prime}(\infty)=0$ and $f^{\prime}(0)=\infty$. 


$$
\begin{gathered}
w_{t}=w\left(k_{t}\right)=f\left(k_{t}\right)-f^{\prime}\left(k_{t}\right) k_{t}, \\
R_{t}=f^{\prime}\left(k_{t}\right) .
\end{gathered}
$$

The capital market clearing condition in per capita terms which results from the optimal savings (14) and optimal number of children (15) becomes:

$$
s_{t}^{*}=n_{t}^{*} h_{t+1} k_{t+1}
$$

Reformulating (20), we get the capital market clearing condition in per human capital terms as:

$$
\frac{\chi \rho\left(h_{t}\right)\left(e+\tau^{c}\right)\left(f\left(k_{t}\right)-f^{\prime}\left(k_{t}\right) k_{t}\right)}{(1-m \psi) \phi \Omega\left(\frac{\psi m\left(e+\tau^{c}\right.}{1-\psi m}\right)^{m}}=k_{t+1} .
$$

The capital market clearing condition depends on the development of the human capital per capita $h_{t}$. The higher the life expectancy, the higher is the capital intensity in the following period. This is caused by the fact that the need to save increases with an increasing life expectancy to realize a decent life style in the last period of life. Consequently, a steady-state equilibrium can only be reached if the life expectancy is constant. According to our assumptions this is the case when $\rho\left(h_{t}\right)=1$. Assuming that this condition is fulfilled, then (20) becomes:

$$
\frac{\chi\left(e+\tau^{c}\right)\left(f\left(k_{t}\right)-f^{\prime}\left(k_{t}\right) k_{t}\right)}{(1-m \psi) \phi \Omega\left(\frac{\psi m\left(e+\tau^{c}\right)}{1-\psi m}\right)^{m}}=k_{t+1}
$$

The model fulfills the conditions of Galor and Ryder [47] for a unique and stable equilibrium. Defining $k^{*}$ as the equilibrium capital intensity, we calculate the derivative $\frac{d k_{t+1}}{d k_{t}}$ and get the stability condition as:

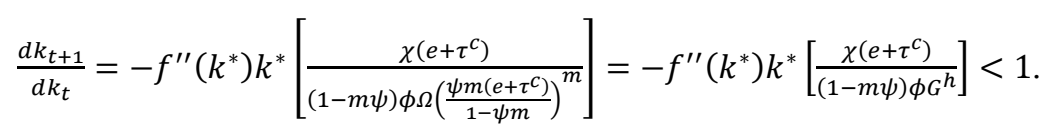

The long-run equilibrium savings $s_{t}^{e}$ and fertility rate $n_{t}^{e}$ is given by:

$$
\begin{aligned}
& s_{t}^{e}=\frac{\left(e+\tau^{c}\right) \chi\left(f\left(k^{*}\right)-f^{\prime}\left(k^{*}\right) k^{*}\right) h_{t}}{\chi\left(e+\tau^{c}\right)+\tau^{c}(1+m \psi \phi)+e(1+\phi)} . \\
& n_{t}^{e}=\frac{\phi(1-\psi m)}{\chi\left(e+\tau^{c}\right)+\tau^{c}(1+m \psi \phi)+e(1+\phi)} .
\end{aligned}
$$

Now we can determine the long-run effects of the one-child policy on the fertility rate and the savings by differentiating (25) and (24), respectively:

$$
\begin{aligned}
& \frac{d n_{t}^{e}}{d \tau^{c}}=-\frac{\phi(1-\psi m)(1+m \psi \phi+\chi)}{\left[\chi\left(e+\tau^{c}\right)+\tau^{c}(1+m \psi \phi)+e(1+\phi)\right]^{2}}<0 . \\
& \frac{d s_{t}^{e}}{d \tau^{c}}=\left.\frac{d s_{t}^{e}}{d \tau^{c}}\right|_{d k=0}+\frac{d s_{t}^{e}}{d k^{*}} \frac{d k^{*}}{d \tau^{c}}>0,
\end{aligned}
$$

where 
$\left.\frac{d s_{t}^{e}}{d \tau^{c}}\right|_{d k=0}=\frac{(1-m \psi) \phi e \chi\left(f\left(k^{*}\right)-f^{\prime}\left(k^{*}\right) k^{*}\right) h_{t}}{\left[\chi\left(e+\tau^{c}\right)+\tau^{c}(1+m \psi \phi)+e(1+\phi)\right]^{2}}>0$,

$\frac{d k^{*}}{d \tau^{c}}=-\frac{\left[\frac{\chi\left(e+\tau^{c}\right)}{(1-m \psi) \phi G^{h}}\right]}{-f^{\prime \prime}\left(k^{*}\right) k^{*}-1}>0$,

$\frac{d s_{t}^{e}}{d k^{*}}=-f^{\prime \prime}\left(k^{*}\right) k^{*} \frac{\left(e+\tau^{c}\right) \chi h_{t}}{\chi\left(e+\tau^{c}\right)+\tau^{c}(1+m \psi \phi)+e(1+\phi)}>0$.

Proposition 3: The introduction or increase of a child tax leads in the long run to a decrease of the fertility rate, and increase of the per capita savings and capital intensity.

And from proposition 3 and proposition 1, we conclude the following proposition.

Proposition 4: The introduction of a child tax increases the per capita income, the wage income and the interest income of all generations born in the introductory period and thereafter.

From proposition 1, it is noted that the growth rate of human capital increases; and from proposition 3 , it is known that the capital intensity increases. Thus, both results taken together lead to the conclusion that the per capita output and the respective factor incomes also increase.

\section{Environmental Impacts: Comparative Statics}

For the environmental impacts caused by the economy, we refer to a modified IPAT model, originally introduced by Ehrlich and Holden [36], where $I$ represents the environmental impact, $P$ the population, $A$ per capita activity and $T$ the technology, which can be interpreted as impact per unit of activity. According to Dietz and Rosa [4], the per capita production can be interpreted as the affluence or activity per capita but the definition of technology is somewhat difficult. In our model, technology is implicitly embodied in human capital. Thus on the one hand, human capital is responsible for developing new production technologies, which increase the labor productivity and hence production, and on the other hand, human capital is also responsible for an improving awareness of environmental issues and developing environmentally friendly technologies, where the latter increases the environmental efficiency of production.

Let us therefore assume that $I_{t}$ represents the GHG emissions in period $t$, which will be generated by the following function:

$$
I_{t}=\Psi y_{t}^{\eta} P_{t}^{\delta} h_{t}^{\gamma}
$$

where $\Psi, \eta, \delta>0, \gamma>-1$ and $P_{t}$ is the total population alive in period t:

$$
P_{t}=N_{t}+N_{t+1}+\rho\left(h_{t}\right) N_{t-1}=\left(1+n_{t}+\frac{\rho\left(h_{t}\right)}{n_{t-1}}\right) N_{t}
$$

The assumption that $\gamma$ can take a negative value means that we do not know which of the two contradicting effects caused by human capital on emissions prevail. If $\gamma$ has a negative sign, the effect of improving environmental efficiency outweighs the negative effect of increasing the production. For 
example, a new central processing unit (CPU) requires less energy but works faster than older CPUs. In the long-run steady-state equilibrium, the population in every period is given by the formula:

$$
P_{t}=\left[\left(n^{*}\right)^{t-1}+\left(n^{*}\right)^{t}+\left(n^{*}\right)^{t-2}\right] N_{1} .
$$

The impact of the child tax is analyzed by differentiating the population with respect to $\tau^{c}$, where we assume that the child tax is introduced in $t=1$ and remains unchanged.

$$
\frac{\partial P_{t}}{\partial \tau^{c}}=\left[(t-1)\left(n^{*}\right)^{t-2}+t\left(n^{*}\right)^{t-1}+(t-2)\left(n^{*}\right)^{t-3}\right] \frac{\partial n^{*}}{\partial \tau^{c}} N_{1}<0,
$$

where $\frac{\partial n^{*}}{\partial \tau^{c}}=-\frac{(1-m \psi) \phi(1+m \psi \phi+\chi)}{\left[\chi\left(e+\tau^{c}\right)+\tau^{c}(1+m \psi \phi)+e(1+\phi)\right]^{2}}<0$ and for $\forall t>2$. The latter condition ensures that in the period of introduction of the child tax, only the number of children can be affected; and in the second period, the number of the old individuals is not affected. From period three on, all vintages will be affected by the tax. This implies the full effect of a child tax will be realized after 2 periods/generations. The number of individuals that will not be born depends on the value of $n^{*}$. If the fertility rate exceeds at least one, the number of individuals born becomes infinite. If the fertility rate is less than one, the value is finite. The sum of changes in population $\Delta P$ up to infinity becomes:

$$
\begin{gathered}
\Delta P=-\frac{\partial n^{*}}{\partial \tau^{c}} N_{1}-\sum_{t=2}^{\infty}\left[\left[(t-1)\left(n^{*}\right)^{t-2}+t\left(n^{*}\right)^{t-1}+(t-2)\left(n^{*}\right)^{t-3}\right] \frac{\partial n^{*}}{\partial \tau^{c}} N_{1}\right] . \\
\Delta P=-\frac{\partial n^{*}}{\partial \tau^{c}} N_{1}\left[1+\left(\frac{\left(n^{*}\right)^{2}-2\left(n^{*}-1\right)}{\left(n^{*}-1\right)^{2}}\right)\right]<0
\end{gathered}
$$

This means the impact of a child tax or the one child policy on the aggregate population of all periods is probably much bigger than the population of the introductory period of the child tax. The reason is that the value of the term in the brackets of the latter equation ranges between 3 and infinity. For example, if the fertility rate is 0.9 , the value of the term in the brackets becomes 299 .

The human capital in period $t$ can be rewritten as:

$$
h_{t}=h_{1}\left(G^{h}\right)^{t-1}=h_{1}\left(\Omega\left(\frac{\psi m\left(e+\tau^{c}\right)}{1-\psi m}\right)^{m}\right)^{t-1}
$$

Differentiating the human capital with respect to the child tax, we get:

$$
\frac{\partial h_{t}}{\partial \tau^{c}}=\frac{(t-1) m h_{1}\left(\Omega\left(\frac{\psi m\left(e+\tau^{c}\right)}{1-\psi m}\right)^{m}\right)^{t-1}}{\left(e+\tau^{c}\right)}=\frac{(t-1) m h_{t}}{\left(e+\tau^{c}\right)}>0
$$

It becomes clear that the human capital will be increased in all periods, with an increasing factor $(t-1)$. For example, the change of human capital in period 10 is $\frac{9 m}{\left(e+\tau^{c}\right)}$ times of the human capital in period 1.

Now, we derive the effect of the child tax on the environmental impact by differentiating (28) and using the results (27), (31) and (34):

$$
\frac{\partial I_{t}}{\partial \tau^{c}}=I_{t}\left[\eta \varepsilon_{y, k} \frac{\left[\frac{\chi\left(e+\tau^{c}\right)}{(1-m \psi) \phi G^{h}}\right]}{1+f^{\prime \prime}\left(k^{*}\right) k^{*}}+\gamma \frac{(t-1) m}{\left(e+\tau^{c}\right)}-\delta \frac{\left[(t-1)\left(n^{*}\right)^{-1}+t+(t-2)\left(n^{*}\right)^{-2}\right]}{\left[\left(n^{*}\right)^{-1}+1+\left(n^{*}\right)^{-2}\right]}\left[\frac{(1+m \psi \phi+\chi)}{\chi\left(e+\tau^{c}\right)+\tau^{c}(1+m \psi \phi)+e(1+\phi)}\right]\right],
$$


where $\varepsilon_{y, k}=\frac{f^{\prime}\left(k^{*}\right) k}{f\left(k^{*}\right)}$ is the production elasticity.

The environmental impact decreases with the introduction or increase of the child tax $\left(\frac{\partial I_{t}}{\partial \tau^{c}}<0\right)$, if $t>$ $\frac{(\mathrm{Y}-\mathrm{X})\left(n^{*}\right)^{2}+\Gamma\left(2+n^{*}\right)}{(\Gamma-\mathrm{X})\left(n^{*}\right)^{2}+\Gamma\left(1+n^{*}\right)^{\prime}}$

where $\mathrm{X}=\frac{\gamma m}{\left(e+\tau^{c}\right)^{\prime}},=\eta \varepsilon_{y, k} \frac{\left[\frac{\chi\left(e+\tau^{c}\right)}{(1-m \psi) \phi G^{h}}\right]}{1+f^{\prime \prime}\left(k^{*}\right) k^{*}}$ and $\Gamma=\frac{\delta(1+m \psi \phi+\chi)}{\left[\left(n^{*}\right)^{-1}+1+\left(n^{*}\right)^{-2}\right]\left[\chi\left(e+\tau^{c}\right)+\tau^{c}(1+m \psi \phi)+e(1+\phi)\right]}$.

Proposition 5: The introduction of a child tax will lead to a decrease of the environmental impact of an economy, at least after a few generations.

Proposition 5 has the following interpretation. It means that it is possible, that it takes a few periods until the emissions will decrease. Important is that the effect on the environmental efficiency of production is sufficiently strong (a relatively small $\mathrm{X}$ ). However, from this comparative static analysis, it is observed that the effect of the one child policy is probably strongly underestimated because the positive environmental impacts are still increasing. Because up to this point, we only have compared steady states, it is not clear what happens on the transition path to the equilibrium. In the next section, we calibrate the model to analyze the transition path to equilibrium.

\section{Calibration of the model}

For the purpose of calibration, we specify a Cobb-Douglas function, written in per human capita form as: 12

$$
y_{t}=A k_{t}^{\alpha}
$$

where $A>0$ and $0<\alpha<1$. Regarding the life expectancy, we apply the following function:

$$
\rho\left(h_{t}\right)=\frac{\beta h_{t}}{1+\beta h_{t}}
$$

with $\beta>0$. Because of the fact that the human capital develops according to

$$
h_{t}=h_{1}\left(\Omega\left(\frac{\psi m\left(e+\tau^{c}\right)}{1-\psi m}\right)^{m}\right)^{t-1}
$$

the life expectancy becomes to:

$$
\rho\left(h_{t}\right)=\frac{\beta h_{1}\left(\Omega\left(\frac{\psi m\left(e+\tau^{c}\right)}{1-\psi m}\right)^{m}\right)^{t-1}}{1+\beta h_{1}\left(\Omega\left(\frac{\psi m\left(e+\tau^{c}\right)}{1-\psi m}\right)^{m}\right)^{t-1}} .
$$

The respective fertility rate becomes to:

\footnotetext{
${ }^{12}$ Guan et al [48] show that the environmental data of China is not very reliable. Hence, calibration becomes more meaningful then regression analysis based on dubious environmental data.
} 


$$
n_{t}^{*}=\frac{\left(1+\beta h_{1}\left(\Omega\left(\frac{\psi m\left(e+\tau^{c}\right)}{1-\psi m}\right)^{m}\right)^{t-1}\right) \phi(1-\psi m)}{\chi \beta h_{1}\left(\Omega\left(\frac{\psi m\left(e+\tau^{c}\right)}{1-\psi m}\right)^{m}\right)^{t-1}\left(e+\tau^{c}\right)+\tau^{c}(1+m \psi \phi)+e(1+\phi)} .
$$

Using these two functions, we derive the difference equation for the evolution of the capital stock per human capital unit as:

$$
k_{t+1}=\frac{(1-\alpha) A k_{t}^{\alpha} \chi \beta h_{1}\left(\Omega\left(\frac{\psi m\left(e+\tau^{c}\right)}{1-\psi m}\right)^{m}\right)^{t-1}\left(e+\tau^{c}\right)\left[\phi\left(e+m \psi \tau^{c}\right)+\left(e+\tau^{c}\right)\left(1+\chi \beta h_{1}\left(\Omega\left(\frac{\psi m\left(e+\tau^{c}\right)}{1-\psi m}\right)^{m}\right)^{t-1}\right)\right]}{\left[\tau^{c}\left(1+\phi \psi m+\chi \beta h_{1}\left(\Omega\left(\frac{\psi m\left(e+\tau^{c}\right)}{1-\psi m}\right)^{m}\right)^{t-1}\right)+e\left(1+\phi+\chi \beta h_{1}\left(\Omega\left(\frac{\psi m\left(e+\tau^{c}\right)}{1-\psi m}\right)^{m}\right)^{t-1}\right)\right](1-\psi m) \Omega\left(\frac{\psi m\left(e+\tau^{c}\right)}{1-\psi m}\right)^{m}} .
$$

The population size is given by:

$$
P_{t}=N_{1} \prod_{i=1}^{t}\left(1+n_{i}^{*}+\frac{\rho\left(h_{i-1}\right)}{n_{i-1}^{*}}\right)
$$

With equations (38)-(42), we assume that $k_{1}=1, h_{1}=1, \mathrm{~b}=0.00025$, adults in period are 0.5, $\mathrm{A}=200$, $\alpha=0.48, \chi=0.7, \phi=0.15, \psi=0.5, \mathrm{~m}=0.41, \mathrm{e}=0.04$, and a period consist of 25 years. The parameter values are reasonable because they fit relatively well to the stylized facts of China and thus the numbers lead to a plausible range of yearly per capita growth rates between 5 and 8 percent. The respective real rates of return are in the range of 8 and 12 percent.

Figure 2 illustrates the evolution of the fertility rate. To examine the impact of the government's child-tax rate on the fertility rate, we define the following periods. Period 1 is from 0 to 33 , Period 2 is from 34 to 66, Period 3 is from 67 to 96, Period 4 is from 97 to 139, and Period 5 is 140 and onwards. The tax rate is zero in Period 1. In Period 2,7\% child-tax rate is introduced. In Period 3 and 4 , the tax rate is lowered to $6 \%$ and $5 \%$, respectively. In the last period, Period 5 , the tax rate is reduced to zero.

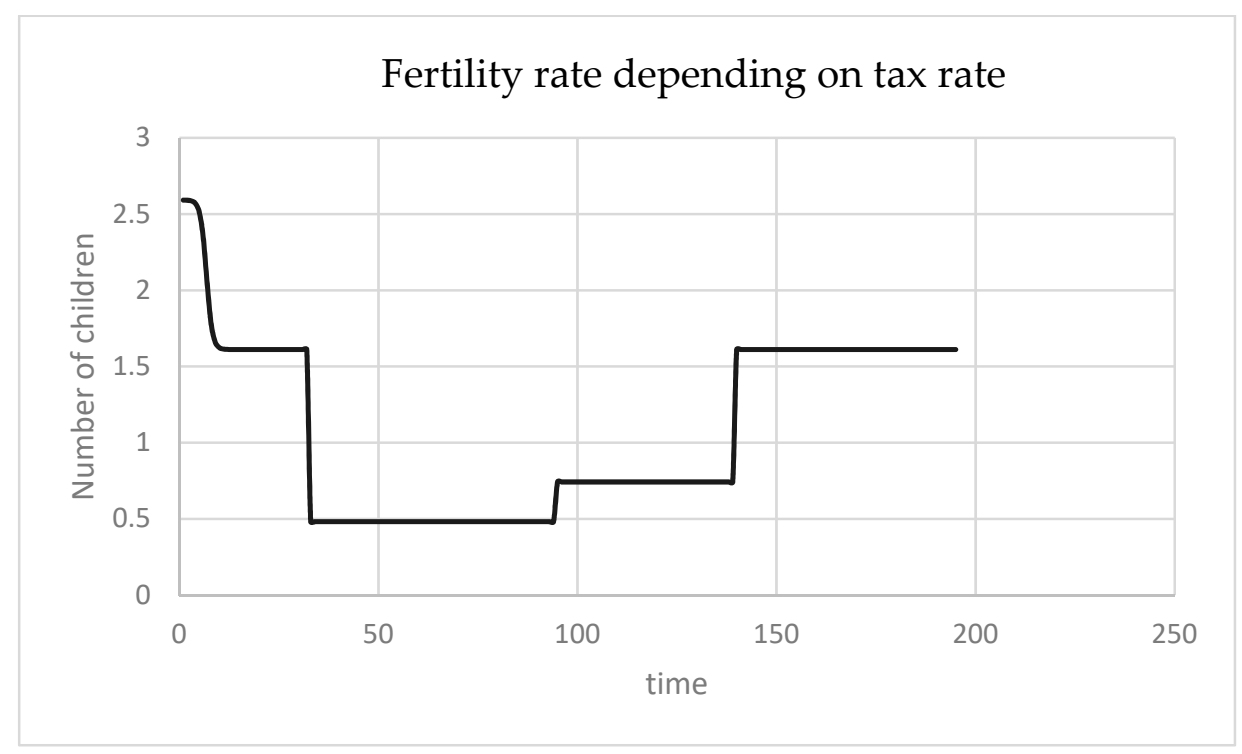

Figure 2

As noted, the number of children is 2.7 in Period 1, without any child-tax, and decreases smoothly with an increasing life expectancy. The introduction of the tax rate of $7 \%$ leads to decline of the fertility 
from around 1.6 children to 0.5 children (Period 2); and lowering the tax rate in Period 3 onwards increases the number of children. Assuming that one period consists of 25-30 years, a tax rate of one percent can be translated into salaries of 3-4 months. And this tax rate coincides roughly with what Chinese citizens had to expect as fine for violating the one child legislation.

Figure 3 shows the evolution of population size (dashed line) and number of adults or workers (solid line). Without a child tax, the population and number of adults would grow indefinitely. The introduction of a child tax therefore results in the decline of both. Because the fertility rate in our calibration is less than one, the population strives to zero in the very long run.

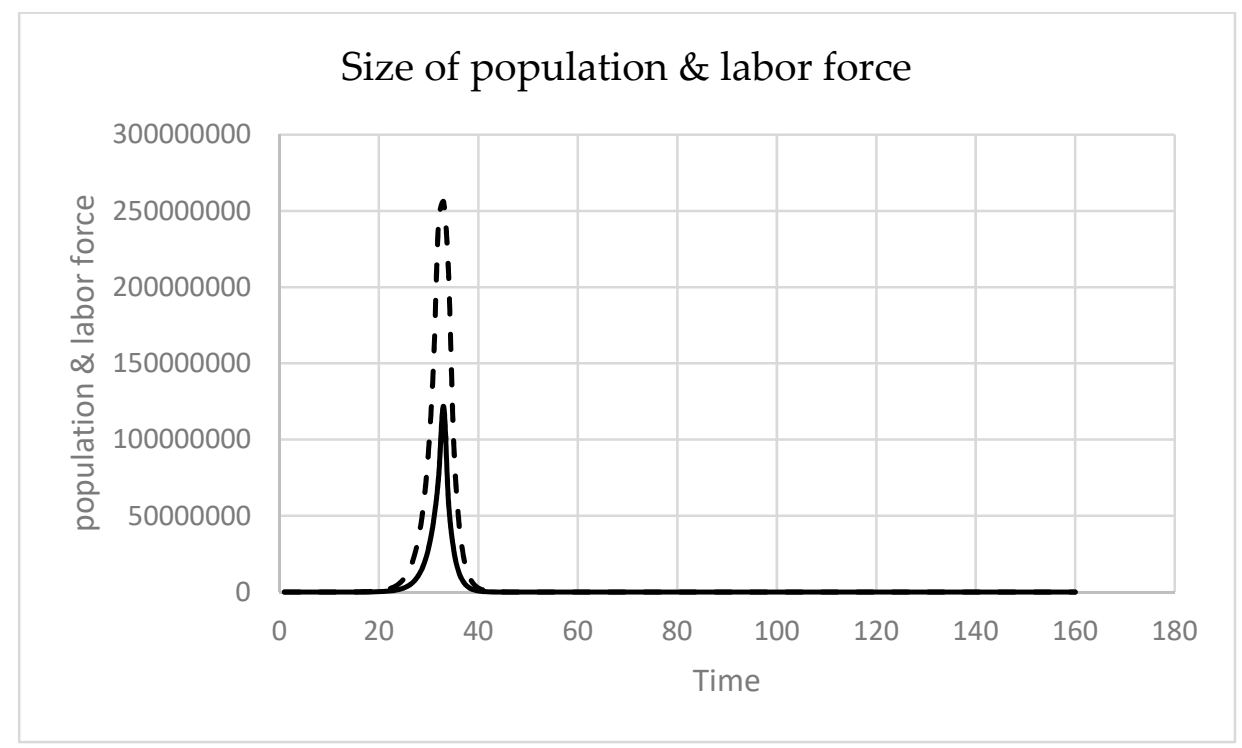

Figure 3

Although Figures 2 and 3 illustrate the transition from a state without tax to a state with tax, the comparative effects caused by the child tax remain ambiguous. To overcome this, we also calibrated the development of three identical economies with three different values of tax rates: $0 \%, 5 \%$ and $7 \%$, respectively and the tax is introduced in period zero. In Figure 4 we present the logarithmic values of the population size with the three tax rates. The graph with the solid line results in the business as usual case without child tax (tax rate is zero). The dotted line represents the case with a child tax of $5 \%$ and the dashed line the case with $7 \%$. Important is to note that the vertical distance between the graphs are increasing, because the distance indicates the difference in the population size under the different tax regimes. The graphs generated with a $5 \%$ and $7 \%$ reach negative values which indicate that the population size strives to zero in the very long run. 


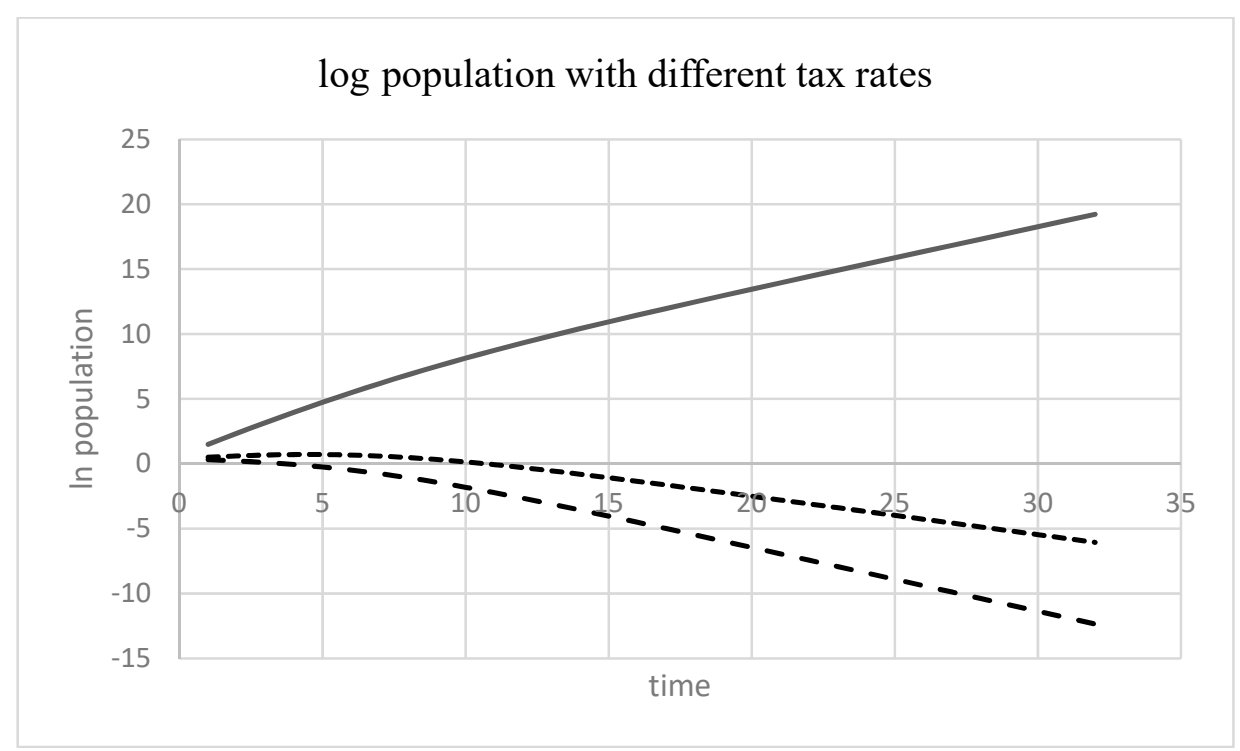

Figure 4

In Figure 5, we consider the wage income as an indicator for the economic well-being. The upper graph (dashed line) illustrates the case of a $7 \%$ tax rate. The dotted line is based on the tax rate of $5 \%$, and the solid line shows the trend with a zero tax rate. It becomes obvious that the wage incomes of the three tax regimes diverge. Obviously, the wage rates diverge in time, indicating that the wage income corresponding to $7 \%$ tax rate grows faster than the wage income corresponding to the $5 \%$ tax rate and the wage income in the business as usual case.

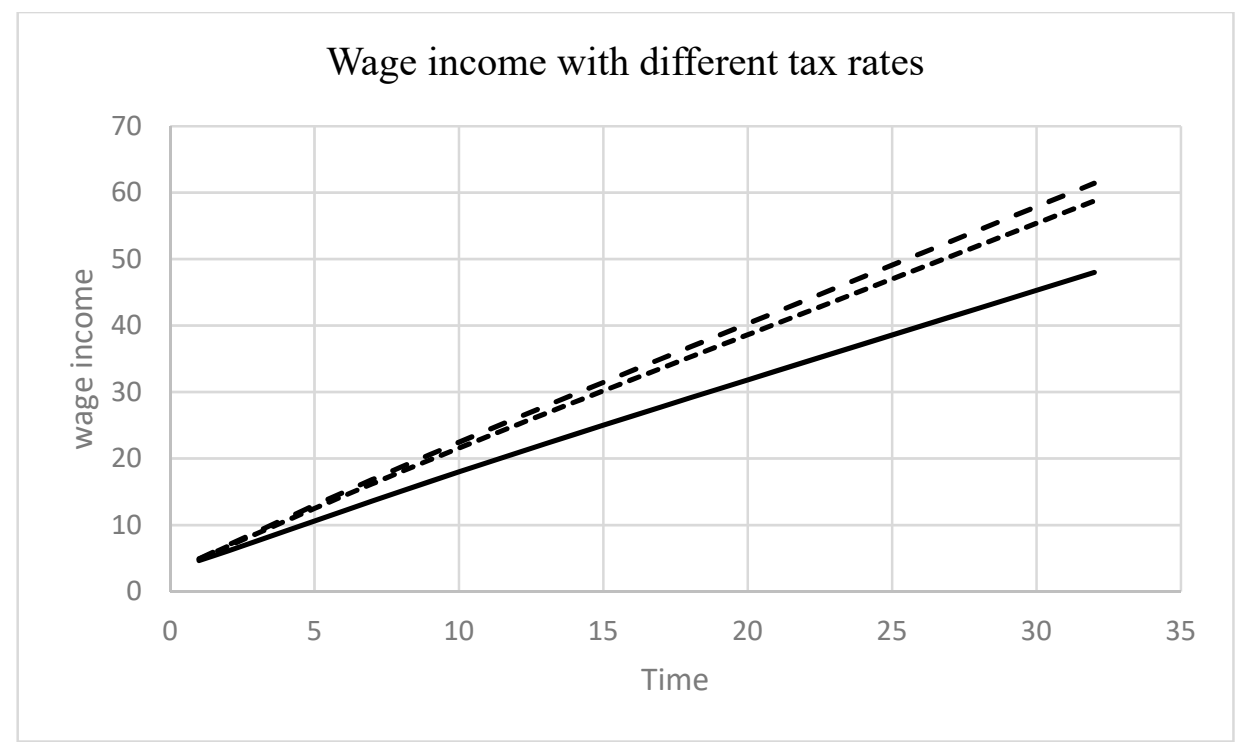

Figure 5

To examine the environmental impact of the one child policy, the value of $\delta$ which is the elasticity of environmental impact with respect to population size, is reviewed. In terms of the elasticity, we note that the empirical literature delivers different values. For instances, Dietz and Rosa [37] and York et al [12] estimate a value close to one, Shi [11] estimates for China, a value between 1.41 and 1.65, Lin [49] 
estimates a lower value of 0.32 for China, and Zhou et al [8] calculate a value of 0.46 for whole China, but a value of 0.31 for the Eastern part of China, a value of 0.39 for central China and a value of 0.77 for the West. However, Harte [50] (p. 224) argues "that the notion that impacts are roughly proportional to our numbers is hugely optimistic. In particular, it [IPAT model] ignores a host of threshold effects, synergies, feedbacks and other nonlinear phenomena that tend to amplify environmental impacts and cause them to grow considerably faster than linearly in population size, even if the per-capita level of affluence and the types of technological systems deployed to achieve that affluence remain constant."

In any case, we note that the stronger the impact of population size is on the environment, the more effective will be the child tax or one-child policy in environmental policy. To support this argument, we consider three cases. Figure 6a illustrates the environmental impact of the child- tax, where we present the logarithms of the environmental impact, and assume the following parameter values: $\Psi=0.001, \eta=$ $0.4, \gamma=0.4$ and $\delta=0.3$. Under these circumstances the influence of population is relatively small and it can be observed that the graphs of the impact under different tax regimes diverge, which means that the reduction of the aggregated emissions over time strives to infinity. However, this means also that a child tax leads to lower levels of emissions, but it does not necessarily reduce emissions to their sustainable levels.

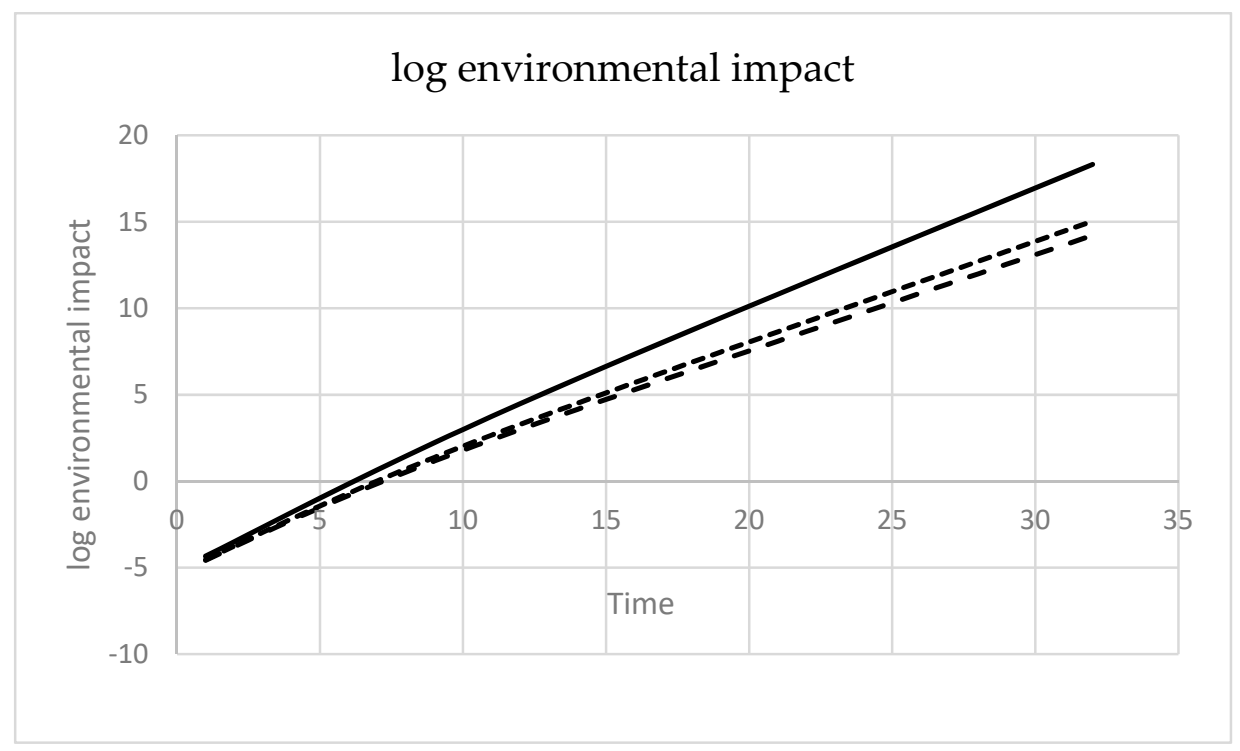

Figure 6a

In Figure 6b, we assume the following parameter values: $\Psi=0.001, \eta=0.4, \gamma=0.4$ and $\delta=1$. The figure shows that as the environmental impact of population becomes stronger, the effectiveness of the child tax increases because the graphs of the environmental impact diverge more than with a lesser impact of population. 


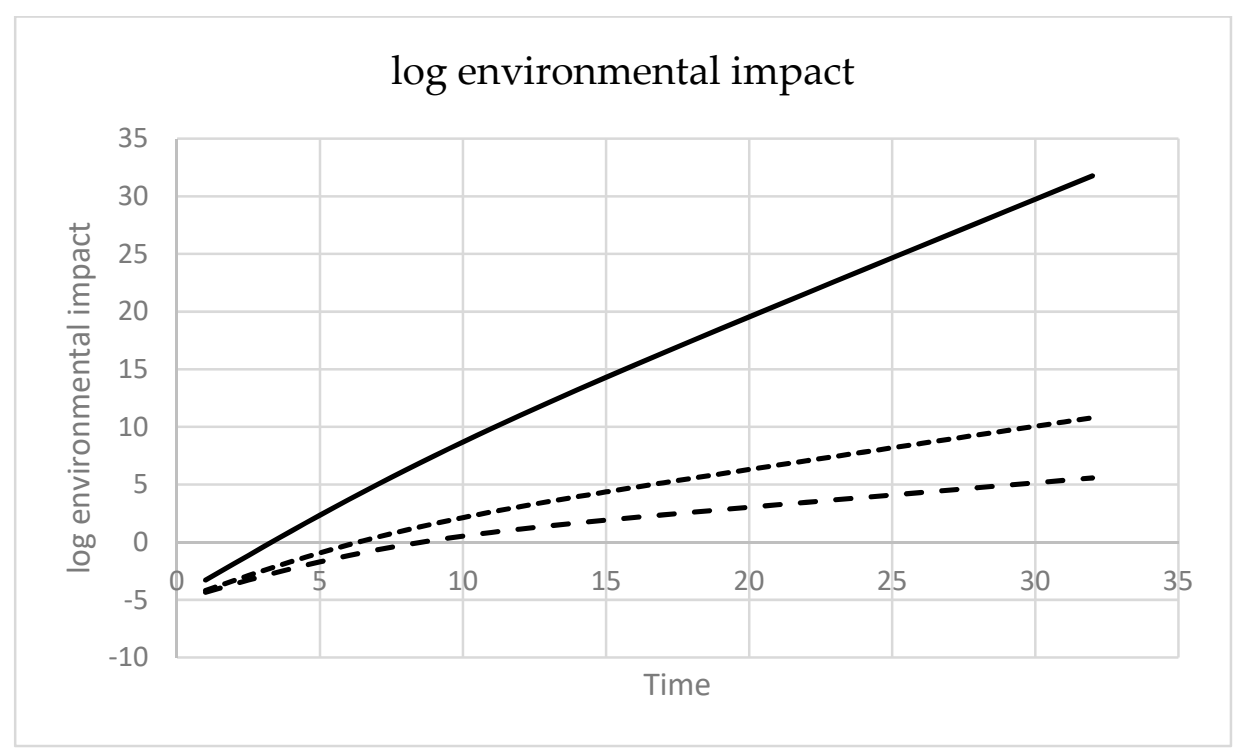

Figure $6 b$

Finally, in Figure 6c, we assume the following parameter values: $\Psi=0.001, \eta=0.2, \gamma=0.2$ and $\delta=$ 1. Under these circumstances the impact of population is assumed to be linear and the environmental effects caused by per capita production are relatively small.

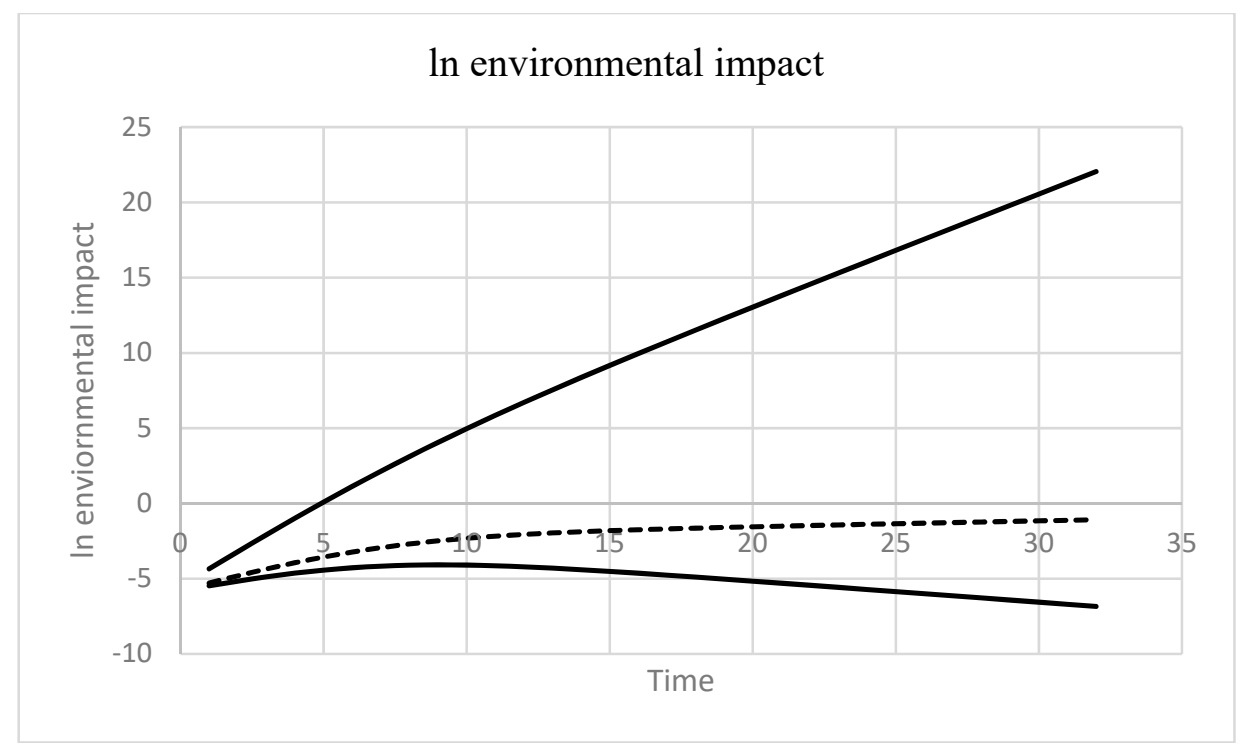

Figure $6 c$

In the business as usual scenario the environmental impact strives to infinity. With a $5 \%$ tax rate the environmental impact increases in time but at much slower speed, and with a $7 \%$ tax rate, the environmental impact decreases after some periods.

In any case, all three scenarios show that the environmental impact is reduced by the introduction of a child tax. Notably, if the impact of the number of individuals is relatively stronger than that of human capital, the total impact of the economy on the environment will strive to zero (Figure $5 c$ ) if the tax rate is 
sufficiently high. Similarly, if the impact of individuals is relatively weaker than that of human capital, the aggregate reduction of emissions caused by a child tax compared to the business as usual case (zerotax rate) will be indefinitely huge.

\section{Conclusions}

We analyzed a population policy similar to the one implemented in China between 1970 and 2015 using an OLG model with endogenous fertility and growth caused by human capital accumulation. To operationalize the one-child policy, we have introduced a child tax, which has the same effect as a monetary fine. We have shown that the economic and environmental impacts of this policy are enormous, because of the long-lasting effects of this policy. The ongoing effects are a consequence of the fact that an unborn person cannot give birth to children and secondly, the additional acquired knowledge through human capital accumulation can be used by future generations without incurring costs. This means, even if the one child policy is applied only on one generation, the effects are relatively strong because the last until infinity. A lesson we can draw from this policy measure is that environmental and development problems can be tackled simultaneously. In general, it can be argued that the higher the current fertility rate, the stronger will be the positive effect caused by a child tax. Thus, the one-child policy or its variant should be considered as one of the preferred development policy in low-income countries. Also, this does not exclude the Western countries from considering the policy for long-term growth and development. Also, it may be politically much easier to implement a child tax than to convince citizens to change their consumption patterns and life styles dramatically in efforts to manage the pressing environmental challenges. Additionally, we have ignored the negative economic effects in our analysis, which are usually associated with environmental degradation [51]. However, the existence of the negative economic feedback mechanisms will give additional support to our proposal.

On the other hand, it cannot be denied that in the period of transition, the problem of aging population will occur once the demographic dividend benefits the respective economies. Thus, by shifting the benefits into the future with decent policy measures, the negative economic impacts of an aging society can be reduced. The results of our study are in line with Peters [52] who derived in a more general model where, in the presence of a pay-as-you-go pension system, a child tax may be a necessary policy instrument to reach a societal intertemporal welfare optimum. ${ }^{13}$

\section{References}

1. Bertoldi, P., Ricci, A., \& de Almeida, A. Energy Efficiency in Househould Appliances and Lighting. Springer Science \& Business Media, Berlin. https://doi.org/10.1007/978-3-642-56531-1

2. Food and Agriculture Organization (FAO) How to feed the world in 2050, Report, 2009, Geneva, http://www.fao.org/fileadmin/templates/wsfs/docs/expert_paper/How_to_Feed_the_World_in_2050.pdf (accessed Feb. 14th, 2018)

3. Ehrlich, P.R. \& Harte, J. Opinion: To feed the world in 2050 will require a global revolution, Proceedings of the National Academy of Sciences. 2015, 112(48), 14743-14744 December 1, 2015. https://doi.org/10.1073/pnas.1519841112

4. Dietz, T., \& Rosa, E. A. Rethinking the environmental impacts of population, affluence and technology. Human Ecology Review, 1994, 1(2), 277-300.

5. Malthus, T. Essay on the principle of population as it affects the future improvement of society, 1798, J. Johnson in St Paul's Church-yard, London https://ia802701.us.archive.org/14/items/essayonprincipl00malt/essayonprincipl00malt.pdf

${ }^{13}$ It should be mentioned that Peters [52] focuses only economic and welfare effects without considering the natural environment. 
6. Ehrlich, Paul R. The Population Bomb, 1968, Ballantine Books, New York

7. Wynes, S., \& Nicholas, K. A. The climate mitigation gap: education and government recommendations miss the most effective individual actions. Environmental Research Letters, 2017,12(7), 074024. http://iopscience.iop.org/article/10.1088/1748-9326/aa7541/pdf. https://doi.org/10.1088/1748-9326/aa7541

8. Zhou, Y., \& Liu, Y. Does population have a larger impact on carbon dioxide emissions than income? Evidence from a cross-regional panel analysis in China. Applied Energy, 2016, 180, 800-809. https://doi.org/10.1016/j.apenergy.2016.08.035

9. Liddle, B., \& Lung, S. Age-structure, urbanization, and climate change in developed countries: revisiting STIRPAT for disaggregated population and consumption-related environmental impacts. Population and Environment, 2010, 31(5), 317-343. https://doi.org/10.1007/s11111-010-0101-5

10. Cole, M. A., \& Neumayer, E. Examining the impact of demographic factors on air pollution. Population $\mathcal{E}$ Environment, 2004, 26(1), 5-21. https://doi.org/10.1023/B:POEN.0000039950.85422.eb

11. Shi, A. The impact of population pressure on global carbon dioxide emissions, 1975-1996: evidence from pooled cross-country data. Ecological Economics, 2003, 44(1), 29-42. https://doi.org/10.1016/S0921-8009(02)00223-9

12. York, R., Rosa, E. A., \& Dietz, T. STIRPAT, IPAT and ImPACT: analytic tools for unpacking the driving forces of environmental impacts. Ecological economics, 2003, 46(3), 351-365. https://doi.org/10.1016/S0921-8009(03)00188-5

13. Poumanyvong, P., \& Kaneko, S. Does urbanization lead to less energy use and lower CO 2 emissions? A crosscountry analysis. Ecological Economics, 2010, 70, 434-444. https://doi.org/10.1016/j.ecolecon.2010.09.029

14. Fan, Y., Liu, L. C., Wu, G., \& Wei, Y. M. Analyzing impact factors of CO 2 emissions using the STIRPAT model. Environmental Impact Assessment Review, 2006, 26(4), 377-395. https://doi.org/10.1016/j.eiar.2005.11.007

15. Martínez-Zarzoso, I., \& Maruotti, A. The impact of urbanization on CO 2 emissions: evidence from developing countries. Ecological Economics, 2011, 70, 1344-1353. https://doi.org/10.1016/j.ecolecon.2011.02.009

16. Murtaugh, P. A., \& Schlax, M. G. Reproduction and the carbon legacies of individuals. Global Environmental Change, 2009, 19(1), 14-20. https://doi.org/10.1016/j.gloenvcha.2008.10.007

17. Zhang, J. The Evolution of China's One-Child Policy and Its Effects on Family Outcomes, Journal of Economic Perspectives. 2017, 31(1), 141-160. https://doi.org/10.1257/jep.31.1.141

18. Becker, G. S. An economic analysis of fertility. In Demographic and economic change in developed countries (pp. 209-240), 1960, Columbia University Press.

19. Becker, G. S., \& Lewis, H. G. On the Interaction between the Quantity and Quality of Children. Journal of Political Economy, 1973, 81(2, Part 2), S279-S288. https://doi.org/10.1086/260166

20. Rosenzweig, M., \& Wolpin, K. I. Testing the Quantity-Quality Fertility Model: The Use of Twins as a Natural Experiment. Econometrica, 1980, 48(1), 227-40. https://doi.org/10.2307/1912026

21. Li, H., Zhang, J., \& Zhu, Y. The quantity-quality trade-off of children in a developing country: Identification using Chinese twins. Demography,2008, 45(1), 223-243. https://doi.org/10.1353/dem.2008.0006

22. Rosenzweig, M. R., \& Zhang, J. Do population control policies induce more human capital investment? Twins, birth weight and China's “one-child" policy. Review of Economic Studies, 2009, 76(3), 1149-1174. https://doi.org/10.1111/j.1467-937X.2009.00563.x

23. Huang, Y. Does A Child Quantity-Quality Trade-Off Exist? Evidence from the One-Child Policy in China. In Annual Conference 2015 (Muenster): Economic Development-Theory and Policy (No. 113215). Verein für Socialpolitik/German Economic Association.

24. Lee, J. Sibling size and investment in children's education: An Asian instrument. Journal of Population Economics, 2008, 21(4), 855-875. https://doi.org/10.1007/s00148-006-0124-5

25. Lee, R., \& Mason, A. Fertility, human capital, and economic growth over the demographic transition. European Journal of Population/Revue européenne de Démographie, 2010, 26(2), 159-182. https://doi.org/10.1007/s10680-0099186-x

26. Barro, R. J. Education and economic growth. Annals of Economics and Finance, 2013, 14(2), 301-328.

27. Tietenberg. T., Lewis, L. (2012). Environmental \& Natural Resource Economics, 9th edition, Pearson, Boston

28. Diamond, P. A. National debt in a neoclassical growth model. The American Economic Review, 1965, 55(5), 11261150.

29. Stauvermann, P. J., \& Kumar, R. R. Sustainability of a Pay-as-you-Go Pension System in a Small Open Economy with Ageing, Human Capital and Endogenous Fertility. Metroeconomica, 2016, 67(1), 2-20. https://doi.org/10.1111/meca.12083 
30. Stauvermann, P. J., \& Kumar, R. R. (2017a). Demographic change, PAYG pensions and child policies. Journal of Pension Economics E Finance (in press), online: https://doi.org/10.1017/S1474747216000299

31. Stauvermann, P. J., \& Kumar, R. R. Enhancing growth and welfare through debt-financed education. Economic research-Ekonomska istraživanja, 2017b, 30(1), 207-222.

32. Stauvermann, P. J., \& Hu, J. (2017). What can China expect from an increase of the mandatory retirement age? Annals of Economics and Finance (forthcoming).

33. De La Croix, D., \& Doepke, M. Inequality and growth: why differential fertility matters. The American Economic Review, 2003, 93(4), 1091-1113. https://doi.org/10.1257/000282803769206214

34. De la Croix, D., \& Doepke, M. Public versus private education when differential fertility matters. Journal of Development Economics, 2004, 73(2), 607-629. https://doi.org/10.1016/j.jdeveco.2003.05.005

35. Cipriani, G. P. Population ageing and PAYG pensions in the OLG model. Journal of Population Economics, 2014, 27(1), 251-256. https://doi.org/10.1007/s00148-013-0465-9

36. Ehrlich, P. R. \& Holdren, J. P. Impact of population growth. Science, 1971, 171(3977), $1212-1217$. https://doi.org/10.1126/science.171.3977.1212

37. Dietz, T., \& Rosa, E. A. Effects of population and affluence on CO2 emissions. Proceedings of the National Academy of Sciences, 1997, 94(1), 175-179. https://doi.org/10.1073/pnas.94.1.175

38. Wei, T. What STIRPAT tells about effects of population and affluence on the environment? Ecological Economics, 2011, 72, 70-74. https://doi.org/10.1016/j.ecolecon.2011.10.015

39. Ehrlich, I., \& Lui, F. T. Intergenerational trade, longevity, and economic growth. Journal of Political Economy, 1991, 99(5), 1029-1059. https://doi.org/10.1086/261788

40. De la Croix, D., \& Doepke, M. To segregate or to integrate: education politics and democracy. The Review of Economic Studies, 2009, 76(2), 597-628. https://doi.org/10.1111/j.1467-937X.2008.00529.x

41. Cutler, D., Deaton, A., \& Lleras-Muney, A. The determinants of mortality. The Journal of Economic Perspectives, 2006, 20(3), 97-120. https://doi.org/10.1257/jep.20.3.97

42. Blackburn, K., \& Cipriani, G. P. A model of longevity, fertility and growth. Journal of Economic Dynamics and Control, 2002, 26(2), 187-204. https://doi.org/10.1016/S0165-1889(00)00022-1

43. Cipriani, G. P., \& Makris, M. PAYG pensions and human capital accumulation: some unpleasant arithmetic. The Manchester School, 2012, 80(4), 429-446. https://doi.org/10.1111/j.1467-9957.2011.02251.x

44. Uzawa, H. Optimum technical change in an aggregative model of economic growth. International Economic Review, 1965, 6(1), 18-31. https://doi.org/10.2307/2525621

45. Lucas, R. E. On the mechanics of economic development. Journal of Monetary Economics,1988, $22(1), 3-42$. https://doi.org/10.1016/0304-3932(88)90168-7

46. Azariadis, C., \& Drazen, A. Threshold externalities in economic development. The Quarterly Journal of Economics, 1990, 105(2), 501-526. https://doi.org/10.2307/2937797

47. Galor, O., \& Ryder, H. E. Existence, uniqueness, and stability of equilibrium in an overlapping-generations model with productive capital. Journal of Economic Theory, 1989, 49(2), 360-375. https://doi.org/10.1016/00220531(89)90088-4

48. Guan, D., Liu, Z., Geng, Y., Lindner, S., \& Hubacek, K. The gigatonne gap in China's carbon dioxide inventories. Nature Climate Change, 2012, 2(9), 672-675. https://doi.org/10.1038/nclimate1560

49. Lin, S., Zhao, D., \& Marinova, D. Analysis of the environmental impact of China based on STIRPAT model. Environmental Impact Assessment Review, 2009, 29(6), 341-347. https://doi.org/10.1016/j.eiar.2009.01.009

50. Harte, J. Human population as a dynamic factor in environmental degradation. Population and Environment, 2007, 28(4-5), 223-236. https://doi.org/10.1007/s11111-007-0048-3

51. Rezai, A., Taylor, L. \& Foley, D. Economic Growth, Income Distribution, and Climate Change, Ecological Economics. 2018, 146 (2018) 164-172. https://doi.org/10.1016/j.ecolecon.2017.10.020

52. Peters, W. Public pensions, family allowances and endogenous demographic change. Journal of Population Economics, 1995, 8(2), 161-183. https://doi.org/10.1007/BF00166650 